\title{
Artificial habitat and biofouling species distributions in an aquaculture seascape
}

\author{
J. Atalah*, L. M. Fletcher, I. C. Davidson, P. M. South, B. M. Forrest \\ Cawthron Institute, 98 Halifax Street East, Nelson 7010, New Zealand
}

\begin{abstract}
The global proliferation of marine artificial habitats is rapidly altering the physical structure of coastlines, with knock-on effects on physical, chemical, and ecological processes at seascape scales. Ecological consequences of maritime sprawl associated with aquaculture are poorly understood, despite the fact that these suspended structures are particularly prone to biofouling, which can affect the industry and seascape around it. We characterised seascape-scale spatial and temporal distribution patterns of 10 biofouling taxa in relation to the presence and distance to Perna canaliculus mussel farms in New Zealand's largest aquaculture region. Seven of 10 taxa had significantly higher cover on farms than in natural habitats throughout the region. The cover of 4 of those 7 taxa, including the high-profile pests Mytilus galloprovincialis and Undaria pinnatifida, exponentially decreased with distance from the nearest farm, while some taxa were absent from natural habitats (e.g. the ascidian Ciona robusta). In contrast, several opportunistic macroalgal species, such as Cladophora ruchingeri and Pylaiella littoralis, had colonised extensive areas of natural habitat. Our results suggest that biofouling is a persistent issue on mussel farms and that farm structures may act as reservoirs or 'stepping stones' for the dispersal of potential marine pests. These distributional and dispersal patterns can inform integrated pest management efforts focusing on spatial management strategies, such as 'firebreaks' in farm connectivity, avoidance of pest hotspots, and farm fallowing.
\end{abstract}

KEY WORDS: Maritime sprawl - Mussel farming - Novel ecosystem - Invasion ecology · Macroalgal blooms $\cdot$ Seascape distributions

\section{INTRODUCTION}

Urban sprawl and the development of agricultural landscapes have had profound impacts on the distribution of organisms and the ecology of ecosystems, promoting certain species and processes that have thrived in highly modified and managed landscapes, while diminishing or eliminating others (Vila \& Ibáñez 2011). On a global scale, the cumulative effect of these novel ecosystems has contributed to unprecedented biotic exchange (invasions) and mass extinctions (Waters et al. 2016). An analogous but less well-understood situation has developed in marine systems with the advent of maritime sprawl — the equivalent of urban sprawl, in which maritime infra-

\footnotetext{
${ }^{*}$ Corresponding author: javier.atalah@cawthron.org.nz
}

structures like seawalls, marinas, docks, floating pontoons, platforms, and other structures are built or installed in marine systems (Airoldi et al. 2005, Firth et al. 2016). The proliferation of artificial habitat in the sea has greatly increased over time, altering the physical structure of coastlines, with knock-on effects on physical, chemical, and ecological processes (Malerba et al. 2019).

One of the most conspicuous ecological features of artificial coastal structures is the distinct marine communities they support in comparison with nearby natural habitats (Glasby et al. 2007). In particular, biofouling species that inhabit the novel environment provided by coastal structures can become highly abundant around these structures, while

() The authors 2020. Open Access under Creative Commons by Attribution Licence. Use, distribution and reproduction are unrestricted. Authors and original publication must be credited. 
remaining absent or occurring only at low densities in adjacent natural habitats (Forrest et al. 2013). The nature of the biofouling assemblage that develops on coastal structures depends on a range of factors, with substratum type (e.g. concrete, wood, polyethylene, metal) and orientation (e.g. vertical vs. horizontal surfaces) providing habitats that suit different species to different degrees (Connell \& Glasby 1999, Glasby \& Connell 2001).

To date, much of the focus on maritime sprawl and ecological community change has been on urban coastlines (Dafforn et al. 2015) and offshore energy installations (Doyle \& Havlick 2009). In contrast, aquaculture development in sheltered coastal environments results in an ongoing proliferation of artificial structures outside urban areas (Gentry et al. 2017). In terms of their role as marine habitats, aquaculture developments differ categorically from urban maritime sprawl. Marine farming typically occurs in relatively remote regions and involves the installation of structures that physically differ from urban coastal hardening. The structures provided by marine farms are often disconnected from the shoreline and usually elevated above the seafloor or suspended on the water surface or in the water column. Off-bottom structures provide a novel hard substrate not present on the seafloor, where benthic predation and sediment accumulation may exert significant control over ecological communities. For example, mussel and finfish farms occupy space that was previously 'open' water (pelagic space) and are without natural analogues. Kelp forests are arguably the nearest equivalent, in that they provide vertical structure many metres in length, similar to bivalve crop lines or net pens, but do not support the development of the substantial biomass of biofouling that occurs on marine farms. The outcome is that marine farming developments provide extensive areas of homogenous nearshore novel habitat, with a range of potential positive and negative repercussions for regional-scale distribution of species and possible effects on ecological processes that have not been well explored to date (McKindsey et al. 2007, Lacoste \& Gaertner-Mazouni 2015).

One of the emerging areas of research in this field is the role of marine farms as reservoir habitats for pest organisms. These are species of native or introduced origin that can become problematic in aquaculture due to their proliferation on marine farm structures (Padilla et al. 2011, Fitridge et al. 2012, Forrest \& Atalah 2017) and which may also affect surrounding benthic species, habitats, or ecosystems (Molnar et al. 2008). An understanding of dispersal potential of biofouling pests into natural habitats and among artificial structures is of particular importance for the design of pest management strategies, such as areas where no farming occurs or 'firebreaks' that disrupt pest dispersal networks, and the spatial scales at which these control measures are feasible (Forrest et al. 2009). Because of the limited adult movement capacity of most biofouling taxa, planktonic propagule dispersal (e.g. larvae, spores) plays a crucial role in farm connectivity and the potential for spread into natural habitats (Pineda et al. 2010). Larval dispersal is dependent on complex interactions between physical and biological processes acting at a range of spatiotemporal scales and is greatly influenced by larval duration and behaviour (e.g. vertical migration or secondary settlement), distance from source populations, and the influence of hydrodynamic processes (Shanks 2009). Furthermore, human activities (e.g. vessel movements, stock and gear transfers) can increase species' dispersal capacity by transporting them across barriers to their natural dispersal, which can greatly accelerate their rate of spread (Floerl \& Inglis 2005, Forrest et al. 2009).

This study examined regional-scale distributions of biofouling organisms in an aquaculture seascape, focusing on a target suite of species (or higher taxa), most of which have previously displayed high localscale abundances or are regarded as pests. The case study region, Pelorus Sound, is the largest aquaculture region in New Zealand and is among the highest production regions for farmed mussels in the world (based on Perna canaliculus, FAO 2018). It also possesses ecological features of national and international interest (e.g. sensitive biogenic habitats, Davidson et al. 2013). Prior studies have quantified the diversity of species that occur on mussel farms in this region (Woods et al. 2012, Watts et al. 2015, South et al. 2019) and elsewhere (Khalaman 2001, de Sá et al. 2007, Sievers et al. 2014), but regional-scale $\left(100 \mathrm{~s}\right.$ of $\left.\mathrm{km}^{2}\right)$ assessments of aquaculture seascapes are lacking. We assessed relationships between conspicuous biofouling species and mussel farm structures and nearby natural habitat, and investigated possible drivers of species distributions. Specifically, we evaluated whether species occurrence and cover were determined by the presence of artificial structures (mussel farms) and whether species distribution in natural habitats was associated with distance from the nearest mussel farm. We also examined the relative importance of physical and biological drivers associated with the establishment and spread of conspicuous biofouling species in natural habitats. The 
results can inform a framework for understanding maritime sprawl in rural areas, its consequences, and possible management initiatives that could benefit farm operations and ecological processes in adjacent natural habitats.

\section{METHODS}

\subsection{Study region}

Pelorus Sound is an intricate system of drowned valleys in the Marlborough Sounds region at the top of the South Island, New Zealand (Fig. 1). The sound stretches approximately $45 \mathrm{~km}$ from the mouth of the Pelorus River at Havelock northward toward Cook Strait. Freshwater inflows from the Pelorus River and semi-diurnal tidal cycles are the main drivers of hydrodynamic variation within the system, affecting salinity, temperature, sedimentation, and productivity gradients along the sound (Gibbs et al. 1991). These

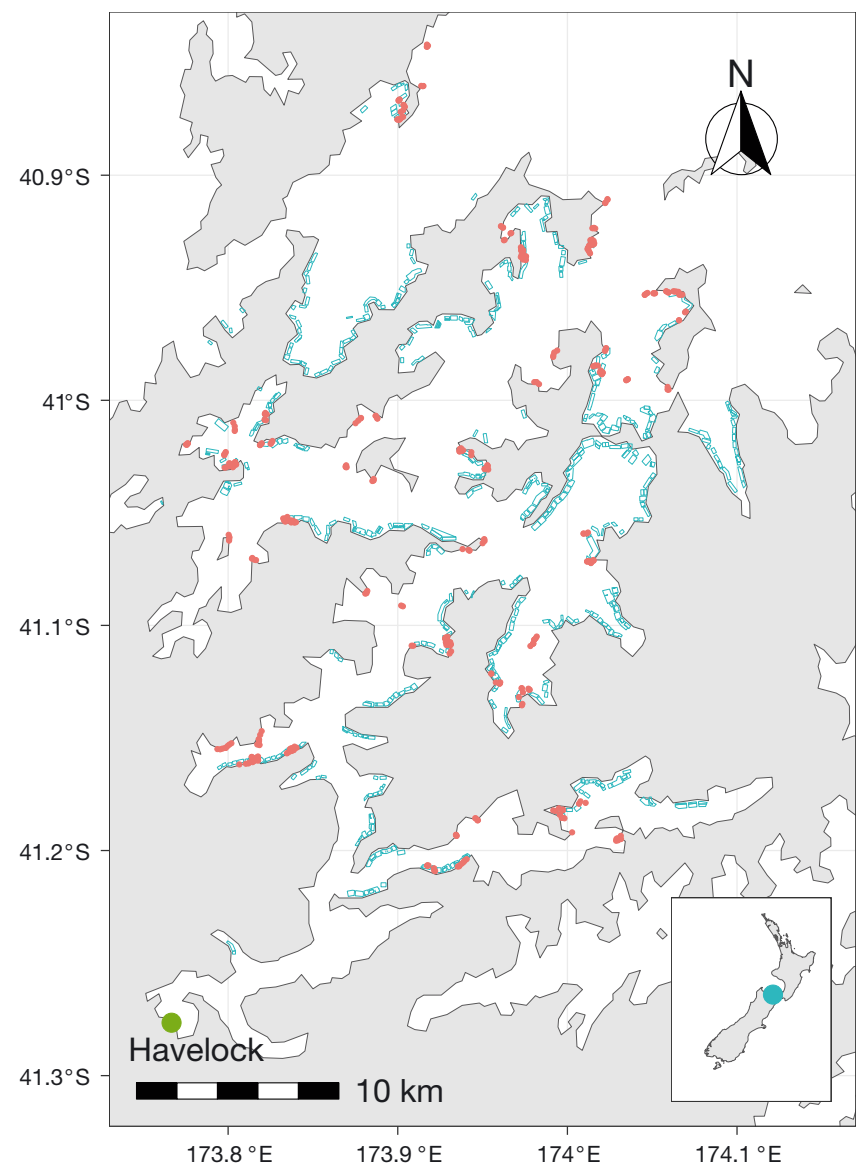

Fig. 1. Map of the study area showing active green-lipped mussel Perna canaliculus farms (blue polygons) and sampling sites (red circles) in Pelorus Sound gradients in environmental conditions can strongly influence diversity, abundance, and composition of benthic assemblages within an aquaculture seascape that has ca. 450 nearshore mussel farms covering an estimated area of 2530 ha. Solid benthic substratum within the system is provided by mussel farm surfaces (crop lines, buoys, backbone lines, and anchor warps), natural rocky and cobble reefs that are primarily restricted to the intertidal and shallow subtidal, and various biogenic habitats.

\subsection{Field surveys}

Regional-scale patterns of 10 prevalent biofouling species were determined by snorkel-based dive surveys, targeting mussel farms and natural hardbottom habitats adjacent to $(<50 \mathrm{~m})$ and distant from $(>50 \mathrm{~m})$ those farms. The surveys targeted animals and marine macroalgae with varying life history traits (Table 1), many of which are a concern for the mussel industry. Target species distributions were assessed along 392 transects throughout Pelorus Sound. Surveys were conducted at the conclusion of the austral summer (12-16 February) and winter (17-21 September) of 2018 to capture an entire season of biofouling growth and regress. Sampling units consisted of $100 \mathrm{~m}^{2}$ transects sampled visually by snorkelers swimming $50 \mathrm{~m}$ in a straight line and observing the area within $1 \mathrm{~m}$ on either side $\left(2 \times 50 \mathrm{~m}^{2}\right)$. Snorkelers estimated the percent cover of each target species across the entire transect. Surveys were conducted by the same 3-person snorkel team in both seasons (J. Atalah, L. M. Fletcher, and B. M. Forrest). Prior to sampling, pilot surveys were conducted to calibrate methods and ensure consistency between team members. This approach allowed for direct comparison of transects, all with a depth range of 0-5 $\mathrm{m}$, at farm sites and natural (non-farm) sites, with 3 replicate transects per site. Surveys of natural habitats were based on horizontal areas of hard substrate (i.e. bedrock or cobble habitats), whereas all farm site surveys focused on a $50 \mathrm{~m}$ length of backbone and the associated $1 \mathrm{~m}$ vertical surface of crop lines and buoys. We avoided farms where crop lines had been recently deployed or reseeded (i.e. crop lines that were not fouled). Additional observations made for each non-farm transect included substratum depth and slope, proportion of substratum types (bedrock, boulder, and cobble), and extent of biogenic habitat (primarily Carpophyllum spp. and Cystophora spp. macroalgal beds). 
Table 1. Annotated list of focal taxa assessed during surveys of the Pelorus Sound region. Relative propagule dispersal distance: $\mathrm{S}=$ short; $\mathrm{M}=$ medium; $\mathrm{L}=$ long. Geographic origin in New Zealand recorded as: $\mathrm{N}=$ native; $\mathrm{UNK}=$ unknown; NIS = non-indigenous

\begin{tabular}{|c|c|c|c|c|c|}
\hline Focal taxa & Description & Propagule types & $\begin{array}{c}\text { Propagule } \\
\text { dispersal }\end{array}$ & Status & $\begin{array}{l}\text { Key } \\
\text { reference }\end{array}$ \\
\hline Ceramiales $^{\mathrm{a}, \mathrm{b}}$ & Red macroalgae & $\begin{array}{l}\text { Spores, fragments, } \\
\text { thalli (gametophytes) }\end{array}$ & S-M & N/UNK & $\begin{array}{l}\text { Edwards } \\
(1973)\end{array}$ \\
\hline Ciona robusta & Solitary ascidian & $\begin{array}{l}\text { Tadpole larvae } \\
\text { (non-feeding) }\end{array}$ & $\mathrm{S}$ & NIS & $\begin{array}{l}\text { Bouchemousse et al. } \\
\text { (2016) }\end{array}$ \\
\hline Cladophora ruchingeri $^{\mathrm{a}}$ & Green filamentous algae & $\begin{array}{l}\text { Spores, gametes/zygotes, } \\
\text { fragments }\end{array}$ & $\mathrm{S}-\mathrm{M}$ & NIS & $\begin{array}{l}\text { Zulkifly et al. } \\
\qquad(2013)\end{array}$ \\
\hline Codium fragile ${ }^{\mathrm{c}}$ & Green macroalga & $\begin{array}{l}\text { Gametes, buds, fragments, } \\
\text { thalli }\end{array}$ & S-M & N/NIS & $\begin{array}{l}\text { Watanabe et al. } \\
\qquad \text { (2009) }\end{array}$ \\
\hline Colpomenia spp. ${ }^{\mathrm{b}}$ & Brown algae & $\begin{array}{l}\text { Spores, gametes/zygotes, } \\
\text { thalli (gametophytes) }\end{array}$ & S-M & N/NIS & $\begin{array}{c}\text { Clayton } \\
\text { (1979) }\end{array}$ \\
\hline Didemnum vexillum & Colonial ascidian & $\begin{array}{l}\text { Tadpole larvae } \\
\text { (non-feeding) }\end{array}$ & $\mathrm{S}$ & NIS & $\begin{array}{l}\text { Fletcher et al. } \\
\quad(2013 b)\end{array}$ \\
\hline Mytilus galloprovincialis ${ }^{\mathrm{d}}$ & Mussel & $\begin{array}{l}\text { Veliger larvae } \\
\text { (feeding) }\end{array}$ & $\mathrm{L}$ & N/NIS & $\begin{array}{l}\text { Toupoint et al. } \\
\text { (2012) }\end{array}$ \\
\hline Pylaiella littoralis ${ }^{\mathrm{a}}$ & Brown filamentous algae & $\begin{array}{l}\text { Spores, gametes/zygotes, } \\
\text { fragments, thalli (gametophytes) }\end{array}$ & S-M & NIS & $\begin{array}{l}\text { Bothwell et al. } \\
\qquad(2010)\end{array}$ \\
\hline Styela clava & Solitary ascidian & $\begin{array}{l}\text { Tadpole larvae } \\
\text { (non-feeding) }\end{array}$ & $\mathrm{S}$ & NIS & $\begin{array}{l}\text { Wong et al. } \\
\text { (2011) }\end{array}$ \\
\hline Undaria pinnatifida & Brown kelp & Spores, thalli & $\mathrm{S}-\mathrm{M}$ & NIS & $\begin{array}{l}\text { South et al. } \\
\text { (2017) }\end{array}$ \\
\hline
\end{tabular}

\subsection{Focal taxa}

The target species comprised 4 invertebrates and 6 macroalgal species or higher taxa (henceforth 'focal taxa') (Table 1 \& Fig. 2). These 10 taxa are conspicuous biofouling species on mussel farms, and some, regardless of their introduction status, are considered pests given their documented impacts on aquaculture in New Zealand and overseas. The 2 solitary ascidians, Ciona robusta and Styela clava, and the colonial ascidian Didemnum vexillum all have relatively short larval durations, limited local dispersal, and are exotic to New Zealand (Ramsay et al. 2009, Goldstien et al. 2010, Fletcher et al. 2013b). The blue mussel Mytilus galloprovincialis has northern and southern hemisphere lineages, with the southern lineage native to New Zealand having experienced invasion, hybridisation, and introgression by northern blue mussels (Gardner et al. 2016). These mussels are broadcast spawners with relatively long larval durations and a high dispersal capability (Toupoint et al. 2012). Ceramiales is a suite of filamentous and finely branched red algal species (including Polysiphonia abscissoides and
Ceramium apiculatum) that commonly co-occur in the region (Woods et al. 2012, South et al. 2019). However, these species can be difficult to identify in the field and represent a complex, poorly understood mix of native and possibly non-indigenous species (Nelson 2013). Cladophora ruchingeri and Pylaiella littoralis are introduced filamentous green algae that have only recently been identified in the study region and are increasingly being recorded on marine farm structures (Pochon et al. 2015). Codium fragile is a green alga, known commonly as dead man's fingers, and likely includes 2 subspecies: C. fragile ssp. tomentosoides and $C$. fragile ssp. novae-zelandiae, considered nonindigenous and native to New Zealand respectively. Colpomenia spp. is a species group, commonly known as bubble weeds, and likely includes 2 species, C. sinuosa and C. peregrina, and possibly a third, C. claytoniae, all of which have global distributions and a complex history of invasions (Boo et al. 2011). The final taxon, Undaria pinnatifida, is an introduced kelp that has become prolific in many areas of New Zealand (South et al. 2017). All focal algal taxa can disperse over small distances via microscopic propagules in- 

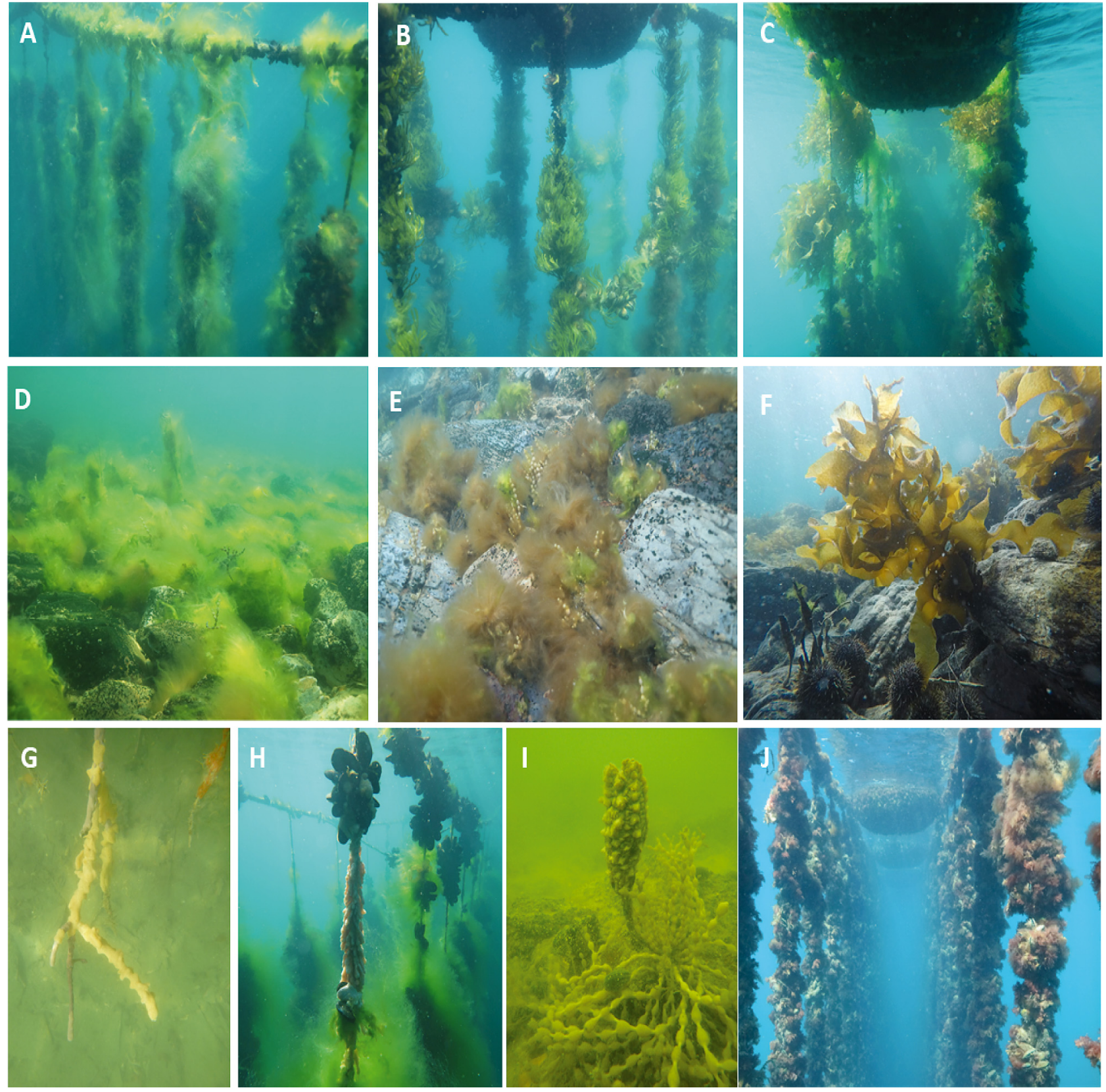

Fig. 2. Representative images of focal taxa growing $(A, B, C, H, J)$ on farms and $(D, E, F, G, I)$ in natural habitats, including $(A, D, H)$ Cladophora ruchingeri, (B) Codium fragile, $(\mathrm{C}, \mathrm{F})$ Undaria pinnatifida, $(\mathrm{E})$ Pylaiella littoralis, $(\mathrm{G}, \mathrm{H})$ Didemnum vexillum, $(\mathrm{H})$ Mytilus galloprovincialis, (I) Styela clava, and (J) Ceramiales

cluding spores or zygotes and over greater distances as a result of drifting reproductive or vegetative thalli that can found new populations (Santelices 1990).

\subsection{Statistical analyses}

Spatiotemporal patterns of biofouling taxa distribution and effect of habitat type were tested using gen- eralised additive models fitted to the percent cover data for each taxon $(\mathrm{n}=392)$ with beta distributed errors and a logit link. Habitat type (2 levels: 'farm' and 'natural') and season (2 levels: 'winter' and 'summer') were both considered fixed effects, whereas latitude and longitude were included as a smoothed interaction to model the spatial dependence of the data. The factor season reflects variability between sampling periods within 2018 and does not allow 
generalisations about inter-annual seasonality. Latitude corresponded to gradients associated with estuarine to oceanic conditions from the inner to outer portions of Pelorus Sound, whereas longitude did not correlate with any obvious regional gradient. To test the hypothesis that marine mussel farms serve as a reservoir for the spread of pests into natural habitats, the cover of each pest in relation to distance from farms was modelled using exponential decay curves. Distance to the closest farm ranged from $0 \mathrm{~m}$ (i.e. farm sites) to a maximum of $4.85 \mathrm{~km}$ for distant sites. Curves were fitted using the formula $y_{d}=y_{0} e^{-b d}$, where $y$ is the percent cover of each taxon at distance $d$ from the nearest farm, $y_{0}$ is the percent cover at the nearest farm (i.e. where $d=0$ ), and $b$ is a constant describing how quickly taxon cover decreases with $d$.

A third analysis was used to identify the relative importance of environmental variables associated with the occurrence of focal taxa in natural habitats, including substrate type and slope, the cover of native canopy-forming algae, and Secchi depth (a proxy for water clarity). For this purpose, beta regression models were fitted to the percent cover data for each taxon obtained from natural habitats $(n=264)$, with percent bedrock, boulder, cobble, Cystophora spp. and Carpophyllum spp., and Secchi depth included as linear effects. Collinearity among predictor variables was assessed using a variance inflation factor. All predictor variables were centered and scaled prior to the analyses (by subtracting the overall mean from each observation and dividing the result by the overall standard deviation), to allow direct comparison of regression coefficients and inference about relative effect sizes among taxa. Model selection was performed using a stepwise process based on the Akaike Information Criterion and validated by inspecting the normalised quantile residuals. All analyses were conducted using $\mathrm{R}$ version 3.6.1 (R Core Team 2019).

\section{RESULTS}

\subsection{Regional pest distribution in relation to habitat and season}

Most focal taxa were found throughout the study region (Fig. 3) at significantly higher cover on mussel farms than in natural habitats $(\mathrm{p}<0.001$, Fig. 4 , Table S1 in the Supplement at www.int-res.com/ articles/suppl/q012p495_supp.pdf). The exceptions were Colpomenia spp., which had similar cover in both habitat types ( $\mathrm{p}>0.05$, Fig. 4, Table S1), and Pylaiella littoralis and Styela clava, which were more prevalent in natural habitats than on farms ( $\mathrm{p}<0.001$, Fig. 4, Table S1). Colpomenia spp. was recorded throughout the region at relatively low cover (mean $\pm \mathrm{SE} ; 1.0 \pm 0.1 \%)$; however, cover increased from south to north ( $p<0.001$, Figs. $3 \&$ S1) and was also highly seasonal, with significantly higher cover in winter than summer ( $\mathrm{p}<0.001$, Fig. 4 , Table S1). $S$. clava was only recorded in 3 bays in inner Pelorus Sound (latitude: $p=0.01$, Figs. $3 \&$ S1), where it was significantly more abundant in natural habitats than on farm structures, particularly during the summer survey (habitat $\times$ season: $\mathrm{p}<0.001$, Fig. 4 , Table S1). Ciona robusta was the only taxon exclusively found on farm structures, particularly on the underside of buoys, where its cover was significantly higher in summer than in winter $(2.3 \pm 0.2$ and $0.6 \pm 0.04 \%$ respectively; habitat $\times$ season $\mathrm{p}<0.001$, Fig. 4). C. robusta was observed on $40 \%$ of the surveyed farms and was more prevalent on farms located in sheltered bays within the inner to mid regions of the Sound (latitude: $\mathrm{p}<0.001$, Figs. $3 \&$ S1).

The colonial ascidian Didemnum vexillum was found almost exclusively on farm structures during both surveys and was present on $93 \%$ of the farms surveyed, with an average cover of $5.5 \pm 0.5 \%$. However, it was also found at relatively low cover $(0.2 \pm 0.05 \%)$ in a few natural habitat sites $(8 \%$ of transects), mainly growing on biogenic features such as erect macroalgae and organic debris, including submerged branches of trees. $D$. vexillum tended to be more prevalent in inner regions of the Sound, but this trend was not significant (Figs. $3 \&$ S1).

Overall, the most abundant and prevalent focal taxon found across the study area was the blue mussel Mytilus galloprovincialis, with cover ranging between 0 and $99 \%$ at any given site and sampling season and an overall mean cover of $21.0 \pm$ $1.4 \%$ (Fig. 3). Blue mussels were present on all farms surveyed and $71 \%$ of the natural habitat transects. However, there was a significant trend of increasing blue mussel cover from south to north (latitude: $p<0.05$ ). Most notably, percent cover of blue mussels was an order of magnitude higher on farm structures than in natural habitats $(54.3 \pm 2.2$ and $4.8 \pm 6.9 \%$ respectively; p < 0.001, Fig. 4). There was a significant habitat $\times$ season interaction driven by lower cover of blue mussels in winter than in summer at farm sites (Fig. 4).

The next most prominent taxon was Ceramiales algae (mean cover $9.9 \pm 1.0 \%$ ), which was broadly recorded throughout the study region, with no dis- 

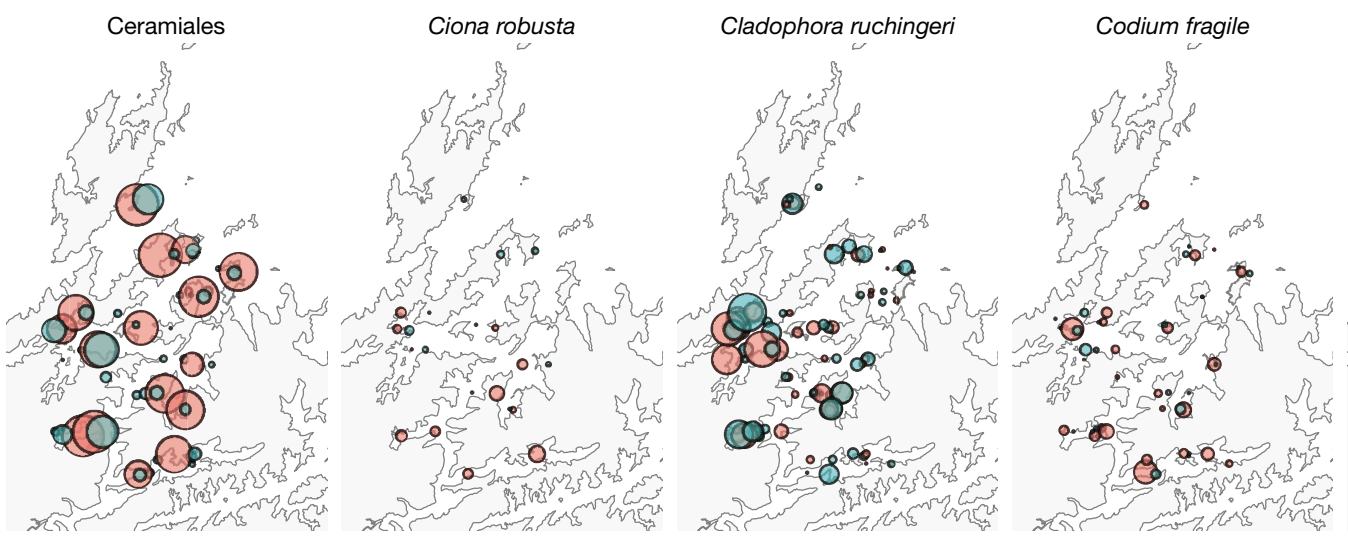

Colpomenia spp.

Didemnum vexillum

Mytilus galloprovincialis
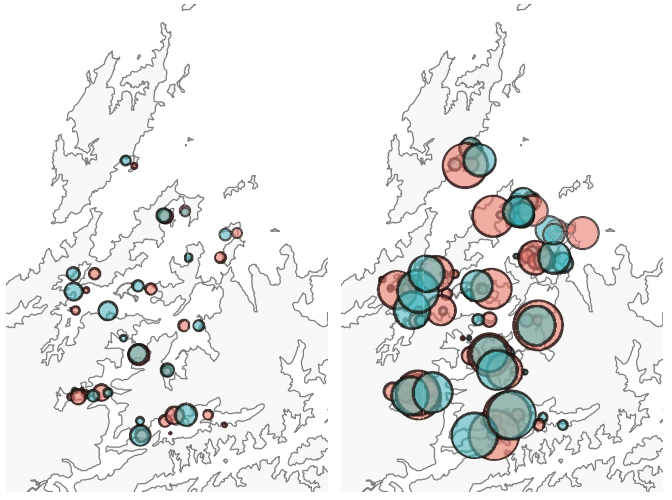

Pylaiella littoralis

Styela clava
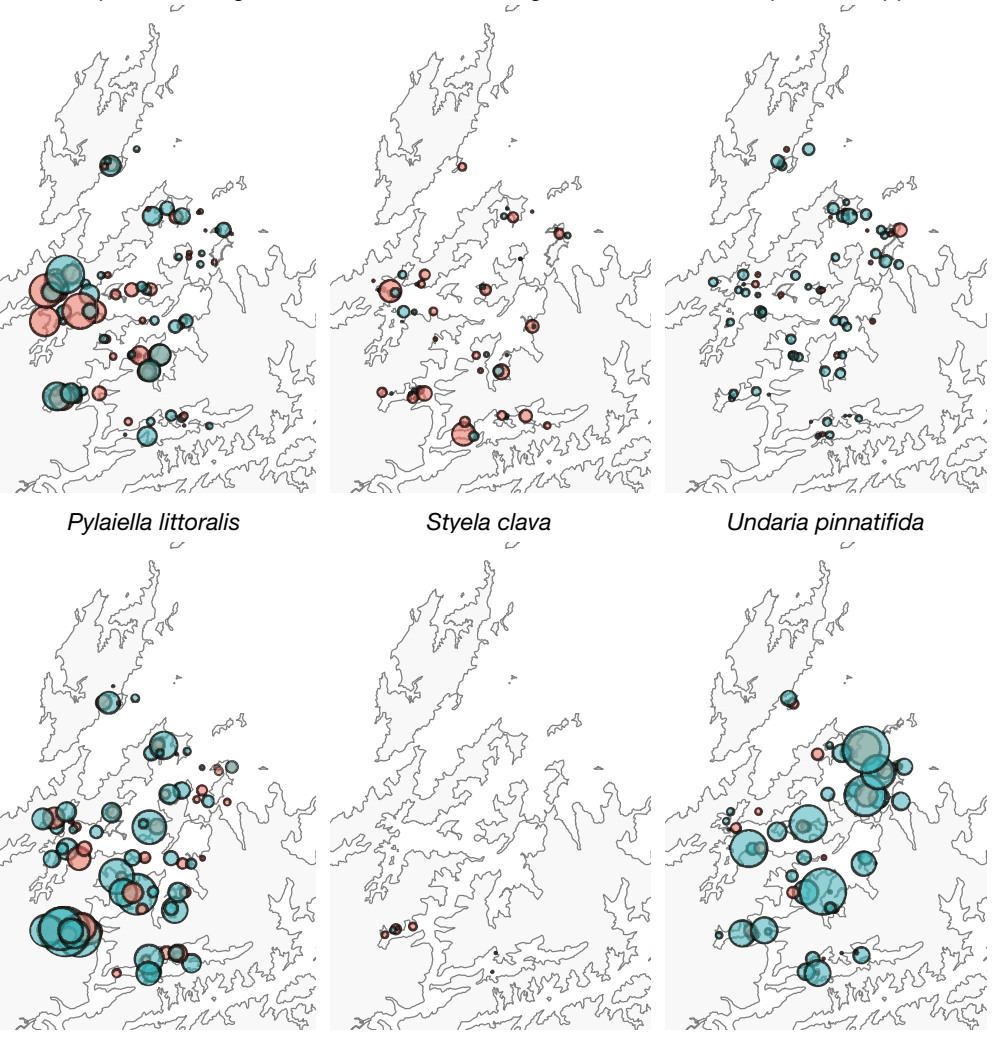

Undaria pinnatifida

Cover: $\bigcirc 25 \bigcirc 50$ $\bigcirc 75$

Season: O Summer o Winter

Fig. 3. Regional distribution of percent cover of the 10 focal taxa surveyed in Pelorus Sound during summer (February 2018) and winter (September 2018)
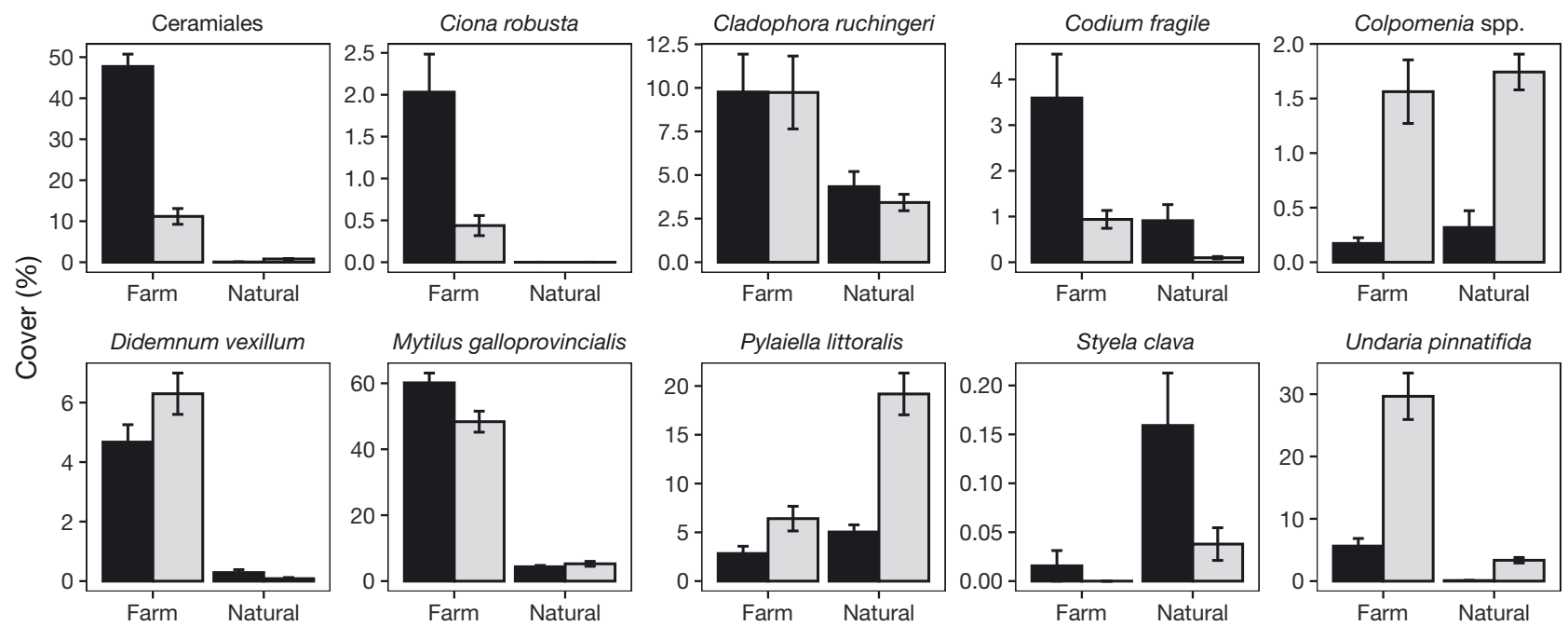

Fig. 4. Mean $( \pm \mathrm{SE})$ percent cover for each focal taxon in relation to habitat type (farm and natural) and sampling season (summer;
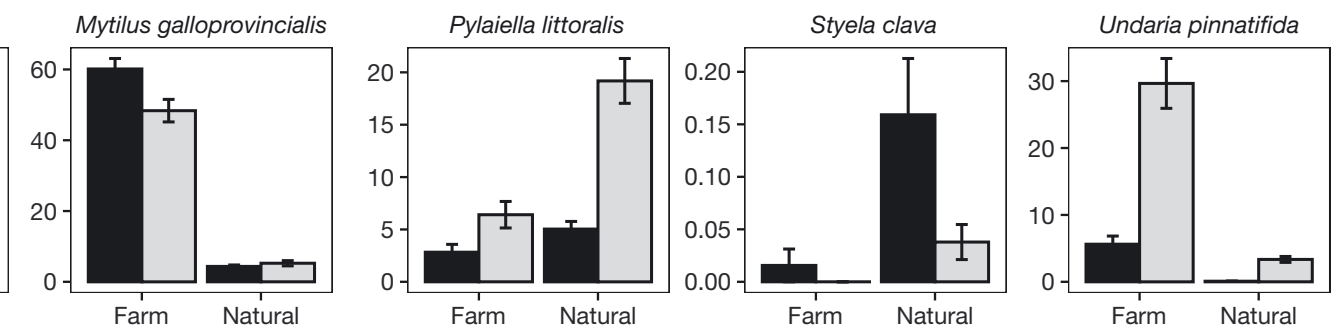

black bars and winter; grey bars)

tinctive geographical pattern. This group was most commonly found on farm sites $(92 \%$ of surveyed farms) with a mean cover of $29.5 \pm 2.4 \%$, but was also found on $20 \%$ of natural habitat transects at a very low level (mean cover $0.5 \pm 0.1 \%$, Fig. 4). Ceramiales species were significantly more abundant during the summer than during the winter, but only on farm sites (habitat $\times$ season: $p<0.001$, Fig. 4). The green fil- 

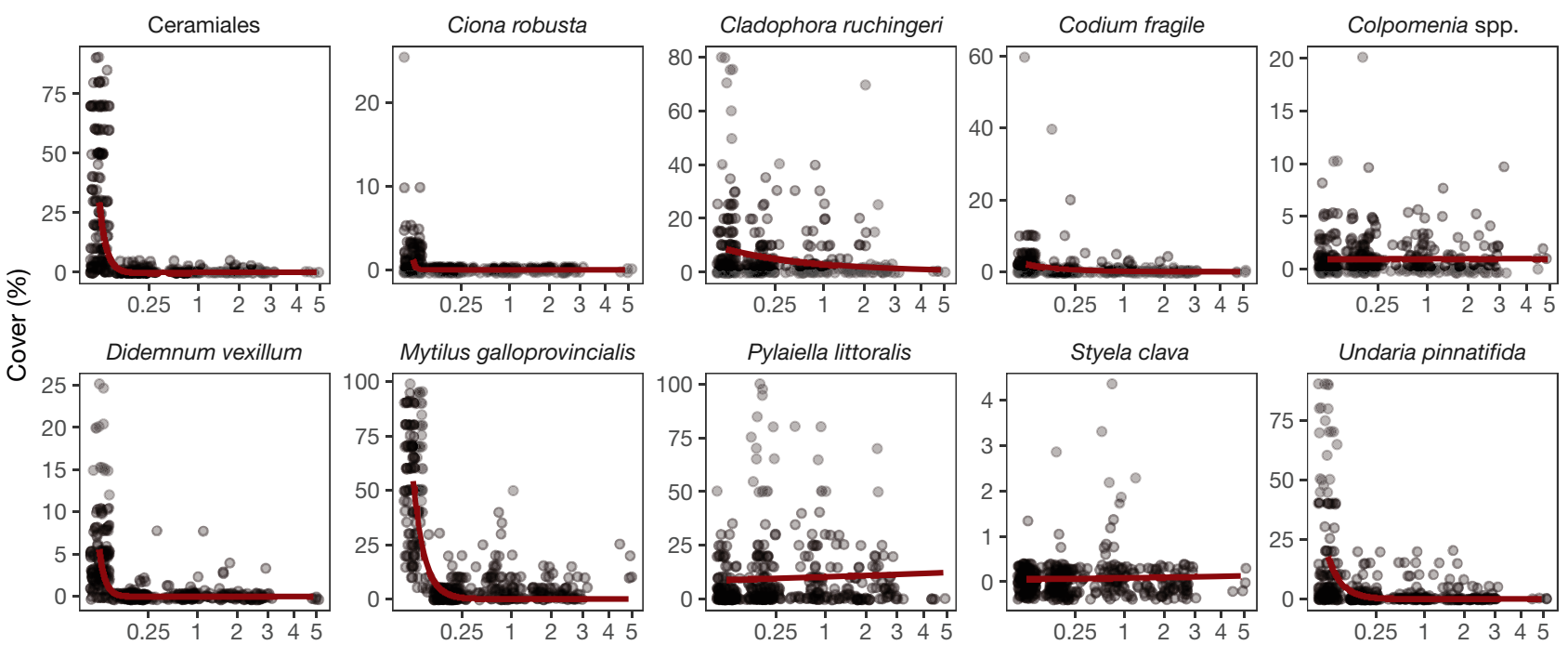

Distance to nearest farm $(\mathrm{km})$

Fig. 5. Exponential decay curves showing predicted reduction in cover of the 10 focal taxa in relation to distance to the nearest mussel farm $(\mathrm{km})$. Note that $x$-axes are in square root scale and $y$-axis scale varies between panels

amentous alga Cladophora ruchingeri was found at 72 and $62 \%$ of farm and natural habitat sites surveyed, respectively, and was more prevalent at eastern sites than western sites (longitude: $\mathrm{p}<0.001$ ). The cover of C. ruchingeri was significantly higher on farms $(9.8 \pm 1.5 \%)$ than in natural habitats $(3.9 \pm$ $0.5 \%$, habitat: $\mathrm{p}<0.001)$ during both surveys. Nonetheless, extensive mats ( $>70 \%$ cover) were sometimes recorded in both habitat types, including growing as an epiphyte on native canopy-forming algae (such as Carpophyllum spp., Hormosira banksii, and Cystophora spp.) in natural habitats. Among the filamentous algae surveyed, the brown alga $P$. littoralis was the most prominent (present on 50 and $70 \%$ of farm and natural habitat transects, respectively). Cover was particularly high in natural habitats during the winter (mean cover $19.2 \pm 2.1 \%$; habitat $x$ season: $p<0.001$, Fig. 4), including $100 \%$ cover of the seabed on some transects (see Fig. 3). Cover of $P$. littoralis was lower on farm structures (mean cover $4.6 \pm 0.7 \%)$.

The cover of Codium fragile was relatively low overall $(1.0 \pm 0.2 \%)$ and was higher on farms than in natural habitats, although this pattern was only significant in summer (habitat $\times$ season: $p<0.001$, Fig. 4). The percent cover of $C$. fragile was higher in southern sites (latitude: $\mathrm{p}<0.01$ ). The distribution of Undaria pinnatifida was highly seasonal; cover was 3 -fold higher on farms than in natural habitats in winter, and $U$. pinnatifida was almost absent from natural habitats in summer (habitat $\times$ season: $\mathrm{p}<0.001$, Fig. 4).

\subsection{Focal taxa cover and distance from novel habitat}

The decay models showed that cover of 4 taxa, namely M. galloprovincialis, U. pinnatifida, C. ruchingeri, and C. fragile, decreased significantly and exponentially with increasing distance from the nearest farm (Fig. 5, Table S2). The most significant rates of decay were estimated for M. galloprovincialis and $U$. pinnatifida ( $\mathrm{b}=-0.035$ and -0.027 , respectively, Table $\mathrm{S} 2$ ). These species exhibited sharp declines in predicted cover with increasing distance, with models predicting $<1 \%$ cover of the 2 taxa at distances $>250$ m away from the nearest farm (Fig. 5). In contrast, C. ruchingeri and $C$. fragile had smaller decay rates $(\mathrm{b}=-0.005$ and -0.007 , respectively, Table S2), indicative of a more gradual decline in cover with increasing distance from the nearest farm (Fig. 5). Predicted cover for C. ruchingeri and $C$. fragile was $<1 \%$ at distances $>750 \mathrm{~m}$ and $>1300 \mathrm{~m}$ from the nearest farm, respectively.

\subsection{Factors associated with taxa occurrence in natural habitats}

Multiple regression identified the relative importance of environmental variables associated with the prevalence of pests in natural habitats. There was a positive relationship between the cover of bedrock and boulder and the cover of $C$. ruchingeri and $M$. galloprovincialis, whereas bedrock had a negative relationship with Colpomenia spp. cover (Fig. 6). Cover of native canopy-forming algae Carpophyllum 

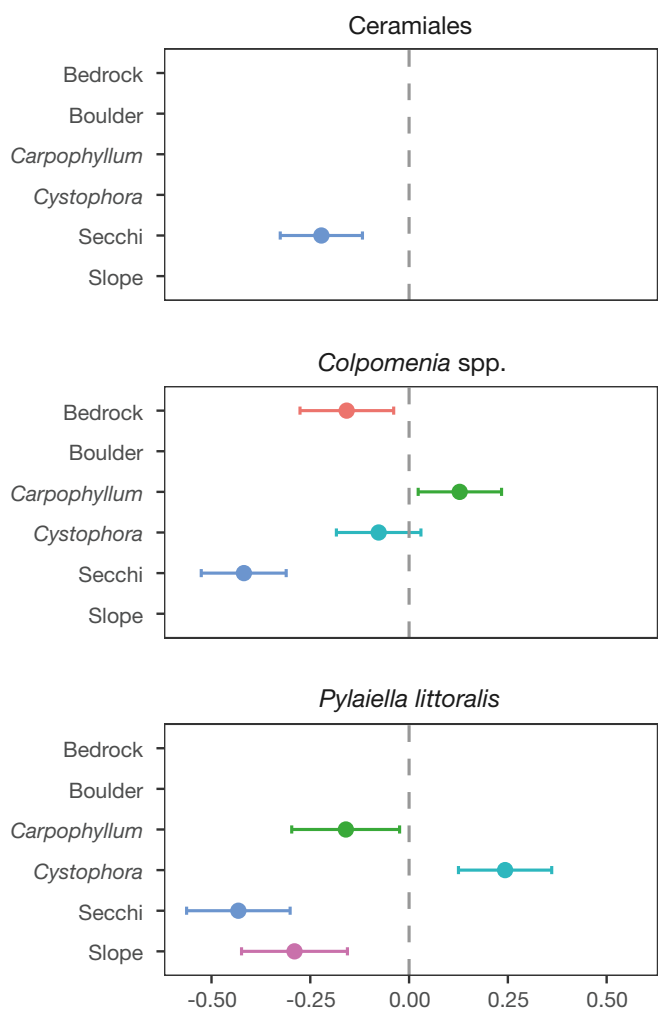
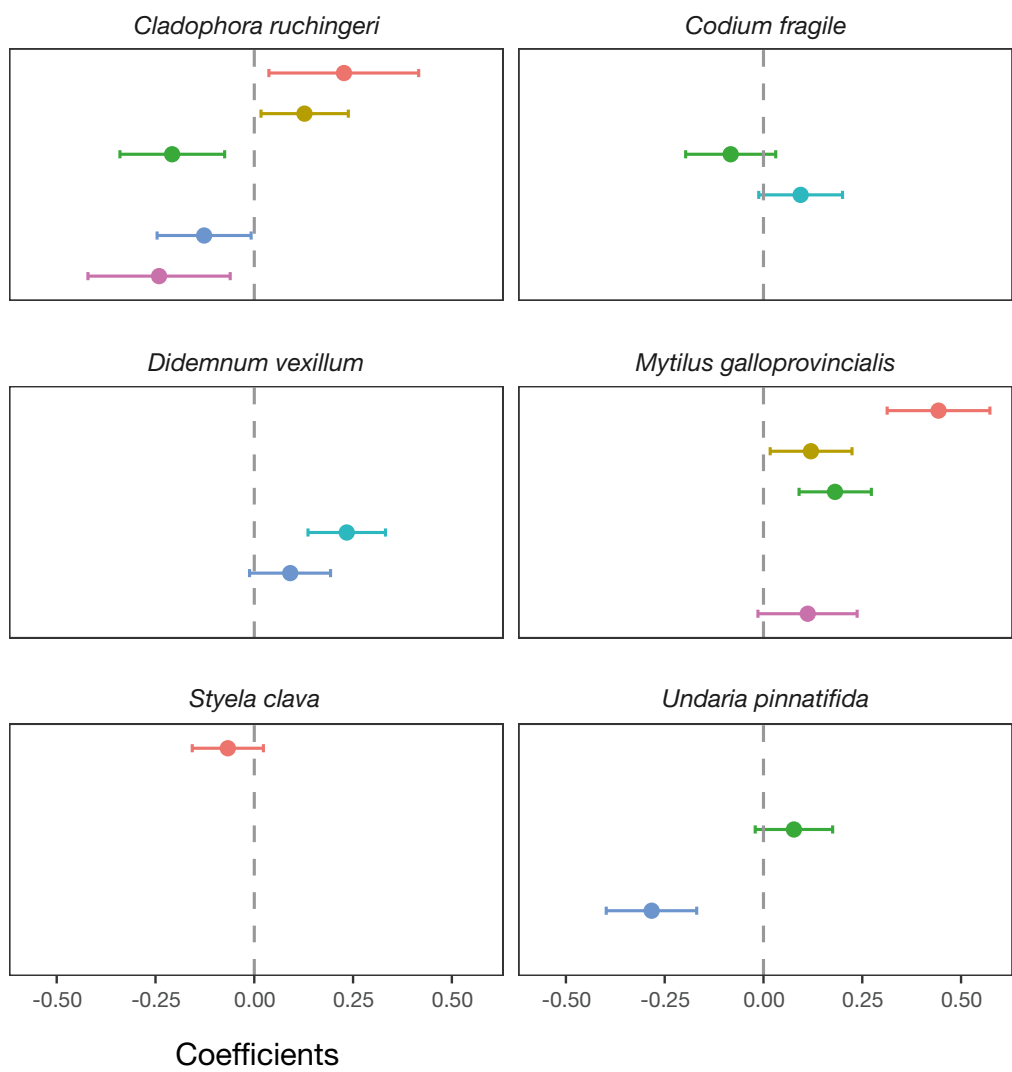

Fig. 6. Coefficients $( \pm 95 \% \mathrm{CI})$ of beta regression models of the percent cover of each focal taxon in response to substrate type (bedrock and boulder), canopy-forming native algae (Carpophyllum spp. and Cystophora spp.), Secchi depth, and substrate slope $(n=264)$. Predictor variables were centred and scaled to allow direct comparison and those not shown were removed during model selection. Statistical significance can be inferred from the overlap of $95 \%$ CI with zero (dotted line). Ciona robusta was not included in this analysis as it was not recorded in natural habitat

spp. and Cystophora spp. were also significant predictors of cover for several focal taxa in natural habitats. For example, Carpophyllum spp. had a positive relationship with Colpomenia spp., M. galloprovincialis, and marginally with $U$. pinnatifida, whereas it was negatively related to the cover of $C$. ruchingeri, C. fragile, and P. littoralis (Fig. 6). Cystophora spp. cover was the strongest predictor of $D$. vexillum and P. littoralis cover (Fig. 6). Secchi depth was negatively associated with the cover of all taxa except $C$. fragile and $D$. vexillum. Substrate slope was negatively related to filamentous algae C. ruchingeri and $P$. littoralis, which were associated with gently sloping habitats, whereas slope was weakly positively related to $M$. galloprovincialis.

\section{DISCUSSION}

The occurrence of focal biofouling taxa in the Pelorus Sound seascape varied dramatically in relation to the widespread provision of novel artificial habitat that occurs throughout the region. Focal taxa distributions were largely determined by the presence of mussel farm infrastructure, with 7 of 10 taxa surveyed being more prevalent on farms than in natural habitats. Four of those 7 taxa showed a significant and exponential decrease in cover with increasing distance from the nearest farm. As previous studies of marine urban settings and offshore installations have shown, novel habitat can differ markedly from the surrounding space in terms of suitability, which can boost or hinder different types of species (Bulleri \& Chapman 2010, Dafforn et al. 2015).

\subsection{Regional pest distributions in relation to habitat and season}

Our results and previous studies show that a significant number of non-crop taxa are facilitated by farm infrastructure (Woods et al. 2012, Lacoste \& GaertnerMazouni 2015). To date, some pest species and broader biofouling assemblages are considered a nuisance to the industry, including taxa with considerable operational and economic impacts. For exam- 
ple, prior work on the blue mussel Mytilus galloprovincialis has shown economic impacts on regional mussel farms, including direct impacts on production and managing costs, of $\$ 16$ million USD per year (Forrest \& Atalah 2017). In this study, M. galloprovincialis was the most abundant and prevalent focal taxon found across the study area, present on all farms surveyed and $71 \%$ of natural habitat transects. Percent cover of this taxon was an order of magnitude higher on farm structures than in natural habitats and it showed the strongest decay in cover with increasing distance from artificial habitat of all species examined. Retention of $M$. galloprovincialis larvae at regional scales raises the possibility that reproduction of abundant populations on aquaculture structures may be a self-perpetuating problem in the Pelorus Sound region (Forrest \& Atalah 2017). The number of blue mussel larvae settling in the region has increased 4-fold over the last 4 decades (Atalah et al. 2017), suggesting a trajectory of increasing impact into the future. It is possible that the significant distance decay model for M. galloprovincialis is explained by secondary migration of juveniles from suspended farm structures into benthic habitat, a pattern observed in many natural systems (Newell et al. 2010, Le Corre et al. 2015).

Globally, economic losses attributed to aquaculture biofouling vary, with estimates ranging from 5 to $30 \%$ of production (Adams et al. 2011) and costs of $\$ 1.5$ to 3 billion USD per year (Fitridge et al. 2012). Biofouling can impact mussel production through different mechanisms, primarily through space competition that displaces juvenile crop, overgrowth that can weigh crop down (and exacerbate crop loss by sloughing), and processing and marketing costs (Fitridge et al. 2012). Biofouling can also impact production by depleting food resources, reducing growth rates of crop species. Negative impacts of biofouling are typically commensurate with abundance or infestation intensity of biofouling pests. In addition to $M$. galloprovincialis, several algae species had strong associations with farm infrastructure in Pelorus Sound, including Ceramiales, Cladophora ruchingeri, and Undaria pinnatifida (Fig. 4). Ascidian species have also shown strong negative impacts on aquaculture in several locations worldwide (e.g. Carver et al. 2003, Davis \& Davis 2010), with variable impacts recorded in New Zealand thus far (Fletcher et al. 2013c). Our results showed that artificial habitat played an exclusive and dominant role in influencing the distributions of the ascidians Ciona robusta and Didemnum vexillum, respectively, but cover of these species was an order of magnitude lower than that of
M. galloprovincialis and some algae. The combined negative effects of fouling and food competition are projected to be significant for New Zealand's shellfish farming sectors if regional outbreaks of filter feeding pests approach $M$. galloprovincialis levels of infestation (Soliman \& Inglis 2018).

As expected, there was significant temporal variability in the cover of most focal taxa, except for Cladophora ruchingeri. Biofouling recruitment and growth is often linked to reproductive cycles and higher water temperature during spring and summer. For example, 4 of the focal taxa had clearly higher cover in summer (Ceramiales, Ciona robusta, Codium fragile, and Styela clava). However, opposite seasonal patterns were recorded for Colpomenia spp. and Undaria pinnatifida because their macroscopic phases are short-lived and tend to occur during the cooler months. These temporal differences varied with habitat type and were generally more pronounced at farms than in natural habitat.

\subsection{Artificial structures as biofouling reservoirs}

An important consideration of maritime infrastructure, including aquaculture within regional seascapes, is its influence on species populations and biodiversity. In this study, farm infrastructure was very suitable habitat for biofouling taxa, which generally colonised it at higher rates than surrounding natural habitats, as occurs for many urban marine man-made structures (Bulleri \& Chapman 2010). Individual farms can support numerous biofouling species and several tons of non-crop biofouling per farm (Woods et al. 2012, Watts 2014). Suspended structures may provide a substratum with optimal light conditions for algae, good access to currents and plankton for animals, and reduced sediment accumulation for all species. They can also provide a refuge from benthic grazing and predation, which may control biofouling pest proliferation in less structured benthic habitats (Atalah et al. 2013, Forrest et al. 2013, James \& Shears 2016). The overall effect can be a local- and regional-scale increase in marine biodiversity, at least in terms of hard-bottom benthic species that would otherwise be limited to seafloor habitat. It has also been suggested that novel farm habitats may replace some historically lost biogenic habitats and their associated biodiversity, as has occurred for natural mussel reefs throughout our study region (Stenton-Dozey \& Broekhuizen 2019). However, mussel farms may not necessarily function in the same manner as natural mussel beds (Strand \& Ferreira 
2019), as they support communities comprising a large proportion of pests and non-indigenous species.

The extent to which sprawling aquaculture installations act as reservoirs of benthic species for the supply and spread of propagules to nearby natural habitats is a key consideration in understanding the role of artificial habitat in regional population dynamics. There are several processes by which farms may act as reservoirs, including through dispersal of planktonic life stages of established fouling organisms and deposition of fouling to the seabed (e.g. deliberate defouling during crop reseeding/harvest or maintenance of buoys and lines). The initial direction of colonisation for species on farm structures is external: species come from surrounding habitats, biofouling on visiting vessels, or fouled infrastructure and seed-stock used for aquaculture production. Over time, however, artificial habitat in farming regions becomes a relatively stable reservoir of biofouling species, despite regular disturbance from crop harvesting, rope replacements, and inter-seed movements, which may promote the proliferation of some opportunistic taxa. The spillover effect of organism dispersal from farm sources can facilitate establishment in natural seafloor habitats, which can have mixed effects. In some cases the refugia of farms can promote population and biodiversity persistence, while in other cases pest populations that might otherwise fail are assisted or accelerated in their spread, with possibly negative effects on biodiversity (Locke et al. 2007, James \& Shears 2016). Of concern in the Pelorus Sound seascape are biofouling species that can sustain large populations and high biomass in natural habitats, such as the opportunistic algae Pylaiella littoralis and C. ruchingeri (Figs. 2 \& 3). Macroalgal blooms are becoming more prominent in many parts of the world (Ye et al. 2011), including our study region (Pochon et al. 2015). When filamentous macroalgae accumulate and proliferate, large areas of seafloor can be colonised, inducing hypoxic conditions and reducing diversity of the benthic community (Gubelit \& Berezina 2010). In some instances, extensive habitat provision by suspended aquaculture structures is implicated in promoting the proliferation of nuisance species, as occurred for one of the largest macroalgal blooms ever reported (Liu et al. 2009).

\subsection{Biofouling dispersal and infiltration of natural habitats}

The mosaic of regional habitats in a seascape, and connectivity among them, is clearly influenced by rural maritime sprawl, simply by the wide extent of this novel habitat type throughout the region. Most of the focal taxa examined here have limited dispersal capacity, reducing their ability to spread naturally to distant sites. For example, spore dispersal of $U$. pinnatifida is limited to tens to hundreds of metres depending on current velocities (Forrest et al. 2000). Similarly, the tadpole larvae of ascidians are competent to settle for a very short time period $(<48 \mathrm{~h})$, which is likely to restrict long distance larval dispersal, requiring stepping stone spread among structures for broader range expansion (Kanary et al. 2011, Fletcher et al. 2013b). Even though M. galloprovincialis has the capacity for long distance dispersal because of a planktonic larval duration of ca. $1 \mathrm{mo}$, its dispersal is highly dependent on local hydrodynamic conditions and it has been observed to recruit within a few kilometres of some source populations (McQuaid \& Phillips 2000). Hydrodynamic modelling studies have revealed the potential for high larval retention in Pelorus Sound, as bays of the inner and mid Pelorus have low water flows $\left(<0.1 \mathrm{~m} \mathrm{~s}^{-1}\right)$ compared to main channel areas $\left(0.2-0.3 \mathrm{~m} \mathrm{~s}^{-1}\right)$, and relatively slow flushing times, ranging from ca. 28 to $50 \mathrm{~d}$ (Gibbs et al. 1991, Broekhuizen et al. 2015). It is possible that these bays act as larval traps, where entrained larvae initially settle on the suspended farm structures and subsequently migrate to benthic habitats at more localised scales (Forêt et al. 2018). For organisms with limited natural dispersal capacity, aquaculture related activities (e.g. vessel and equipment movements, stock transfers) can increase distributional range by anthropogenic transport, greatly accelerating rates of spread. In the case of filamentous algae, thalli can drift in the water following their dislodgement during reseeding, cleaning, and harvesting of crop lines. Floating fragments can settle, attach, and grow on substrates, or accumulate as free living beds over extensive areas of shallow coastal habitats (Paalme et al. 2002). As such, dense networks of artificial structures associated with shellfish farming can provide broad connectivity, by themselves or in conjunction with other habitats, allowing biofouling organisms to cover greater distances over potentially unsuitable areas of habitat (Bulleri \& Airoldi 2005, Forrest et al. 2009). This is particularly relevant for many rural seascapes, where islands of hard-bottom habitat are often isolated from each other in broader areas of soft-sediment seafloor.

The ability of biofouling pests to establish in natural habitats is highly variable among species (Simkanin et al. 2012). For example, in this study the globally common aquaculture pest $C$. robusta was only recorded on farms, likely because it cannot overcome physico- 
biotic resistance to establishment in natural habitats (Dumont et al. 2011). Similarly, the distribution of the highly invasive ascidian $D$. vexillum in natural habitats was limited to erect biogenic structures, such as native algal canopies or submerged trees that provide a refuge from predation (see Forrest et al. 2013). In contrast, aquaculture structures did not promote the occurrence of the introduced sea squirt Styela clava in the region; it was found in greater abundance in natural habitats. It has a propensity to occur on shellfish farms elsewhere (e.g. Arsenault et al. 2009) and its status in the Pelorus Sound possibly reflects $S$. clava's short residence time in the study region to date. First records of $S$. clava in the region date from ca. 2015, resulting in comparatively little opportunity for population development and spread, as also reflected in its localised distribution. Time is one of the highestranking determinants of introduced species spread (Byers et al. 2015) and monitoring regional S. clava populations may be a high priority to understand regional habitat connectivity patterns as well as potential impacts on mussel farming.

\subsection{Implications for ecosystem functioning}

At wider ecosystem scales, the proliferation of suspension feeding biofouling organisms (e.g. ascidians, bryozoans, hydroids, and other bivalves) may have a severe 'trophic footprint'. Suspension feeders have been shown to be the dominant component of marine farm biofouling communities globally (Lesser et al. 1992, de Sá et al. 2007, Daigle \& Herbinger 2009), comprising up to $\sim 88 \%$ of the biomass on farms in our study region (Woods et al. 2012). When present in large numbers, the high filtration rate of ascidians in particular has been shown to cause a dramatic reduction in the availability of phytoplankton and suspended organic matter at a larger scale (Riisgård \& Larsen 2000). Similarly, in urban artificial structures the estimated energy consumption of $1 \mathrm{~m}^{2}$ of invertebrate-dominated biofouling can negate the primary production of up to $130 \mathrm{~m}^{2}$ of surrounding habitat (Malerba et al. 2019). Deposition of farm wastes may also cause wider ecosystem changes to benthic habitat surrounding farms. Current industry practice involves stripping and reseeding mussels onto new ropes at lower densities 1-2 times during the production cycle. This reseeding serves a dual purpose, as it not only thins the mussels out to a more productive stocking density, but also removes or reduces the effects of biofouling. Associated biofouling is typically discarded to the sea floor after separation from cultured stock and rope, which can represent significant episodic localised benthic biodeposition. An assessment of biofouling accumulation at 2 farms in our study region showed $\sim 600 \mathrm{~kg}$ dry weight of biofouling would theoretically have been discarded in total beneath the 2 farms at reseeding and final harvest (Woods et al. 2012). Waste deposition in this manner can lead to organic enrichment of sediments, decreased oxygen levels, and changes to biodiversity of an area (Forrest \& Creese 2006). Considering there are ca. 450 farms located in the Pelorus Sound region alone, this process is likely to represent an ecologically significant stressor to the wider environment. Alternative management methods for this deposition process would probably be prohibitively expensive and may increase risk of pest spread if they involve transporting biofouling elsewhere. Nonetheless, the potential pest spread into natural habitats from artificial structures should be minimised to mitigate cumulative effects that can contribute to ecosystem level tipping points, dead zones, and biodiversity loss (Lubchenco \& Petes 2010).

\subsection{Management implications}

Current industry practices to manage biofouling typically involve mechanical equipment (spray washers, tumblers) at the harvesting stage to clean fouling from crop. Broader management strategies to control shellfish biofouling mostly rely on physical and chemical treatments, such as manual removal, air exposure, power washing, or acetic acid and freshwater baths (Fitridge et al. 2012, Sievers et al. $2014,2019)$. These methods are generally very logistically onerous and difficult to apply at production scales. Knowledge-based management alternatives focusing on pest prevention or avoidance could prove more realistic and cost-effective to mitigate the impacts of biofouling on shellfish production and natural ecosystems. Distributional patterns and modelling approaches that integrate regional hydrodynamic processes can also help to identify 'firebreaks' to pest dispersal. For example, establishing barriers that disconnect pest populations by fallowing key 'stepping stones' connecting distant locations can be an effective strategy for reducing spread, as suggested for controlling the spread of parasites in salmon farms (Samsing et al. 2019) and of C. robusta in mussel farms (Kanary et al. 2011). Key to the success of these strategies is understanding pest impacts (for cost-benefit analyses) and obtaining long-term biofouling monitoring and surveillance data to allow 
predictions around seasonality of settlement. Spatial and temporal patterns of biofouling distribution can inform the timing of husbandry practices, such as spat catching, re-stocking, manual cleaning, and stock transfers, to mitigate potential economic impacts (e.g. Fletcher et al. 2013a).

Accordingly, biofouling distributional patterns and drivers of establishment in natural habitats, as presented here, not only provide crucial baseline information, but also key knowledge for integrated pest management strategies. In the face of the rapid global proliferation of rural maritime sprawl and its potential for transforming seascapes, sound operational practices coupled with effective knowledgebased management strategies are crucial to ensure the sustainable growth of the aquaculture industry and the protection of natural ecosystems.

Data archive. The data and $\mathrm{R}$ scripts used in the analyses are available at https://github.com/jatalah/marine_pest_distribution. Results can be interactively explored at https://cawthron. shinyapps.io/pest_distribution_in_an_aquaculture_seascape/.

Acknowledgements. This study was funded by the Ministry for Business Innovation and Employment Strategic Science Investment Fund Cawthron Institute Science Platform Shellfish Aquaculture (CAW1801). Thanks to James Brodie and Mark Hodren (Marlborough Commercial Diving Services Ltd.) for their assistance with field logistics, and Dr. Konstanze Steiner and Dr. Xavier Pochon (Cawthron Institute) for molecular identification of Pylaiella littoralis. Thanks to New Zealand's Marine Farming Association for facilitating access to marine farms.

\section{LITERATURE CITED}

Adams CM, Shumway SE, Whitlatch RB, Getchis T (2011) Biofouling in marine molluscan shellfish aquaculture: a survey assessing the business and economic implications of mitigation. J World Aquacult Soc 42:242-252

Airoldi L, Abbiati M, Beck MW, Hawkins SJ and others (2005) An ecological perspective on the deployment and design of low-crested and other hard coastal defence structures. Coast Eng 52:1073-1087

Arsenault G, Davidson J, Ramsay A (2009) Temporal and spatial development of an infestation of Styela clava on mussel farms in Malpeque Bay, Prince Edward Island, Canada. Aquat Inv 4:189-19

Atalah J, Hopkins GA, Forrest BM (2013) Augmentative biocontrol in natural marine habitats: persistence, spread and non-target effects of the sea urchin Evechinus chloroticus. PLOS ONE 8:e80365

Atalah J, Rabel H, Forrest BM (2017) Modelling long-term recruitment patterns of blue mussels Mytilus galloprovincialis: a biofouling pest of green-lipped mussel aquaculture in New Zealand. Aquacult Environ Interact 9:103-114

Boo SM, Lee KM, Cho GY, Nelson W (2011) Colpomenia claytonii sp. nov. (Scytosiphonaceae, Phaeophyceae) based on morphology and mitochondrial cox3 sequences. Bot Mar 54:159-167
Bothwell JH, Marie D, Peters AF, Cock JM, Coelho SM (2010) Role of endoreduplication and apomeiosis during parthenogenetic reproduction in the model brown alga Ectocarpus. New Phytol 188:111-121

Bouchemousse S, Bishop JD, Viard F (2016) Contrasting global genetic patterns in two biologically similar, widespread and invasive Ciona species (Tunicata, Ascidiacea). Sci Rep 6:24875

Broekhuizen N, Hadfield M, Plew D (2015) A biophysical model for the Marlborough Sounds, part 2: Pelorus Sound. NIWA client report no. CHC2014-130, National Institute of Water and Atmospheric Research, Christchurch

Bulleri F, Airoldi L (2005) Artificial marine structures facilitate the spread of a non-indigenous green alga, Codium fragile ssp tomentosoides, in the north Adriatic Sea. J Appl Ecol 42:1063-1072

Bulleri F, Chapman MG (2010) The introduction of coastal infrastructure as a driver of change in marine environments. J Appl Ecol 47:26-35

B Byers JE, Smith RS, Pringle JM, Clark GF and others (2015) Invasion expansion: time since introduction best predicts global ranges of marine invaders. Sci Rep 5:12436

Carver CE, Chisholm A, Mallet al. (2003) Strategies to mitigate the impact of Ciona intestinalis (L.) biofouling on shellfish production. J Shellfish Res 22:621-631

Clayton MN (1979) The life history and sexual reproduction of Colpomenia peregrina (Scytosiphonaceae, Phaeophyta) in Australia. Br Phycol J 14:1-10

Connell SD, Glasby TM (1999) Do urban structures influence local abundance and diversity of subtidal epibiota? A case study from Sydney Harbour, Australia. Mar Environ Res 47:373-387

* Dafforn KA, Glasby TM, Airoldi L, Rivero NK, Mayer-Pinto M, Johnston EL (2015) Marine urbanization: an ecological framework for designing multifunctional artificial structures. Front Ecol Environ 13:82-90

พ Daigle RM, Herbinger CM (2009) Ecological interactions between the vase tunicate (Ciona intestinalis) and the farmed blue mussel (Mytilus edulis) in Nova Scotia, Canada. Aquat Invasions 4:177-187

Davidson R, Duffy C, Gaze P, Baxter A, du Fresene S, Courtney S, Hamill P (2013) Ecologically significant marine sites in Marlborough: protocol for receiving and assessing new sites and reassessing existing sites. Survey and monitoring report prepared by Davidson Environmental for Marlborough District Council and Department of Conservation, Blenheim

* Davis MH, Davis ME (2010) The impact of the ascidian Styela clava Herdman on shellfish farming in the Bassin de Thau, France. J Appl Ichthyology 26:12-18

* Doyle MW, Havlick DG (2009) Infrastructure and the environment. Annu Rev Environ Resour 34:349-373

№mont CP, Gaymer CF, Thiel M (2011) Predation contributes to invasion resistance of benthic communities against the non-indigenous tunicate Ciona intestinalis. Biol Invasions 13:2023-2034

Edwards P (1973) Life history studies of selected British Ceramium species. J Phycol 9:181-184

FAO (2018) The state of world fisheries and aquaculture 2018 - meeting the sustainable development goals. FAO, Rome. www.fao.org/3/i9540en/I9540EN.pdf

Firth LB, Knights AM, Bridger D, Evans AJ and others (2016) Ocean sprawl: challenges and opportunities for biodiversity management in a changing world. Oceanogr Mar Biol Annu Rev 54:189-262 
Fitridge I, Dempster T, Guenther J, Nys Rd (2012) The impact and control of biofouling in marine aquaculture: a review. Biofouling 28:649-669

Fletcher L, Forrest B, Atalah J, Bell J (2013a) Reproductive seasonality of the invasive ascidian Didemnum vexillum in New Zealand and implications for shellfish aquaculture. Aquacult Environ Interact 3:197-211

*Fletcher LM, Forrest BM, Bell JJ (2013b) Natural dispersal mechanisms and dispersal potential of the invasive ascidian Didemnum vexillum. Biol Invasions 15:627-643

Fletcher LM, Forrest BM, Bell JJ (2013c) Impacts of the invasive ascidian Didemnum vexillum on green-lipped mussel Perna canaliculus aquaculture in New Zealand. Aquacult Environ Interact 4:17-30

Floerl O, Inglis GJ (2005) Starting the invasion pathway: the interaction between source populations and human transport vectors. Biol Invasions 7:589-606

Forêt M, Tremblay R, Neumeier U, Olivier F (2018) Temporal variation of secondary migrations potential: concept of temporal windows in four commercial bivalve species. Aquat Living Resour 31:19

Forrest BM, Atalah J (2017) Significant impact from blue mussel Mytilus galloprovincialis biofouling on aquaculture production of green-lipped mussels in New Zealand. Aquacult Environ Interact 9:115-126

Forrest BM, Creese RG (2006) Benthic impacts of intertidal oyster culture, with consideration of taxonomic sufficiency. Environ Monit Assess 112:159-176

Forrest BM, Brown SN, Taylor MD, Hurd CL, Hay CH (2000) The role of natural dispersal mechanisms in the spread of Undaria pinnatifida (Laminariales, Phaeophyta). Phycologia 39:547-553

Forrest BM, Gardner JP, Taylor MD (2009) Internal borders for managing invasive marine species. J Appl Ecol 46: $46-54$

Forrest BM, Fletcher LM, Atalah J, Piola RF, Hopkins GA (2013) Predation limits spread of Didemnum vexillum into natural habitats from refuges on anthropogenic structures. PLOS ONE 8:e82229

Gardner JPA, Zbawicka M, Westfall KM, Wenne R (2016) Invasive blue mussels threaten regional scale genetic diversity in mainland and remote offshore locations: the need for baseline data and enhanced protection in the Southern Ocean. Glob Change Biol 22:3182-3195

* Gentry RR, Froehlich HE, Grimm D, Kareiva P and others (2017) Mapping the global potential for marine aquaculture. Nat Ecol Evol 1:1317-1324

Gibbs M, James M, Pickmere S, Woods P, Shakespeare B, Hickman R, Illingworth J (1991) Hydrodynamic and water column properties at six stations associated with mussel farming in Pelorus Sound, 1984-85. N Z J Mar Freshw Res 25:239-254

Glasby TM, Connell SD (2001) Orientation and position of substrata have large effects on epibiotic assemblages. Mar Ecol Prog Ser 214:127-135

* Glasby TM, Connell SD, Holloway MG, Hewitt CL (2007) Nonindigenous biota on artificial structures: could habitat creation facilitate biological invasions? Mar Biol 151: 887-895

* Goldstien SJ, Schiel DR, Gemmell NJ (2010) Regional connectivity and coastal expansion: differentiating pre-border and post-border vectors for the invasive tunicate Styela clava. Mol Ecol 19:874-885

Gubelit YI, Berezina NA (2010) The causes and consequences of algal blooms: the Cladophora glomerata bloom and the Neva estuary (eastern Baltic Sea). Mar Pollut Bull 61:183-188

James K, Shears NT (2016) Proliferation of the invasive kelp Undaria pinnatifida at aquaculture sites promotes spread to coastal reefs. Mar Biol 163:34

*Kanary L, Locke A, Watmough J, Chassé J, Bourque D, Nadeau A (2011) Predicting larval dispersal of the vase tunicate Ciona intestinalis in a Prince Edward Island estuary using a matrix population model. Aquat Invasions 6:491-506

Khalaman V (2001) Succession of fouling communities on an artificial substrate of a mussel culture in the White Sea. Russ J Mar Biol 27:345-352

Lacoste E, Gaertner-Mazouni N (2015) Biofouling impact on production and ecosystem functioning: a review for bivalve aquaculture. Rev Aquacult 7:187-196

* Le Corre N, Johnson LE, Smith GK, Guichard F (2015) Patterns and scales of connectivity: temporal stability and variation within a marine metapopulation. Ecology 96: 2245-2256

KLesser MP, Shumway SE, Cucci T, Smith J (1992) Impact of fouling organisms on mussel rope culture: interspecific competition for food among suspension-feeding invertebrates. J Exp Mar Biol Ecol 165:91-102

*Liu D, Keesing JK, Xing Q, Shi P (2009) World's largest macroalgal bloom caused by expansion of seaweed aquaculture in China. Mar Pollut Bull 58:888-895

* Locke A, Hanson JM, Ellis KM, Thompson J, Rochette R (2007) Invasion of the southern Gulf of St. Lawrence by the clubbed tunicate (Styela clava Herdman): potential mechanisms for invasions of Prince Edward Island estuaries. J Exp Mar Biol Ecol 342:69-77

Lubchenco J, Petes LE (2010) The interconnected biosphere: science at the ocean's tipping points. Oceanography (Wash DC) 23:115-129

* Malerba ME, White CR, Marshall DJ (2019) The outsized trophic footprint of marine urbanization. Front Ecol Environ 17:400-406

*McKindsey CW, Landry T, O'Beirn FX, Davies IM (2007) Bivalve aquaculture and exotic species: a review of ecological considerations and management issues. J Shellfish Res 26:281-294

*McQuaid C, Phillips T (2000) Limited wind-driven dispersal of intertidal mussel larvae: in situ evidence from the plankton and the spread of the invasive species Mytilus galloprovincialis in South Africa. Mar Ecol Prog Ser 201:211-220

* Molnar JL, Gamboa RL, Revenga C, Spalding MD (2008) Assessing the global threat of invasive species to marine biodiversity. Front Ecol Environ 6:485-492

Nelson WA (2013) New Zealand seaweeds: an illustrated guide. Te Papa Press, Wellington

Newell CR, Short F, Hoven H, Healey L, Panchang V, Cheng G (2010) The dispersal dynamics of juvenile plantigrade mussels (Mytilus edulis L.) from eelgrass (Zostera marina) meadows in Maine, USA. J Exp Mar Biol Ecol 394:45-52

Paalme T, Kukk H, Kotta J, Orav H (2002) 'In vitro'and 'in situ' decomposition of nuisance macroalgae Cladophora glomerata and Pilayella littoralis. In: Orive E, Elliott M, de Jonge VN (eds) Nutrients and eutrophication in estuaries and coastal waters. Proc 31st Symp of the Estuarine and Coastal Sciences Association (ECSA), Bilbao, 3-7 July 2000. Springer, Dordrecht

Padilla DK, McCann MJ, Shumway SE (2011) Marine invaders and bivalve aquaculture: sources, impacts, and 
consequences. In: Shumway SE (ed) Shellfish aquaculture and the environment. Wiley-Blackwell, Oxford, p 395-424

Pineda J, Porri F, Starczak V, Blythe J (2010) Causes of decoupling between larval supply and settlement and consequences for understanding recruitment and population connectivity. J Exp Mar Biol Ecol 392:9-21

*Pochon X, Atalah J, Wood SA, Hopkins GA, Watts A, Boedeker C (2015) Cladophora ruchingeri (C. Agardh) Kützing, 1845 (Cladophorales, Chlorophyta): a new biofouling pest of green-lipped mussel Perna canaliculus (Gmelin, 1791) farms in New Zealand. Aquat Invasions 10:123-133

R Core Team (2019) R: A language and environment for statistical computing. R Foundation for Statistical Computing, Vienna

Ramsay A, Davidson J, Bourque D, Stryhn H (2009) Recruitment patterns and population development of the invasive ascidian Ciona intestinalis in Prince Edward Island, Canada. Aquat Invasions 4:169-176

Riisgård HU, Larsen PS (2000) Comparative ecophysiology of active zoobenthic filter feeding, essence of current knowledge. J Sea Res 44:169-193

Sá FSd, Nalesso RC, Paresque K (2007) Fouling organisms on Perna perna mussels: is it worth removing them? Braz J Oceanogr 55:155-161

Samsing F, Johnsen I, Treml EA, Dempster T (2019) Identifying 'firebreaks' to fragment dispersal networks of a marine parasite. Int J Parasitol 49:277-286

Santelices B (1990) Patterns of reproduction, dispersal and recruitment in seaweeds. Oceanogr Mar Biol Annu Rev 28:177-276

Shanks AL (2009) Pelagic larval duration and dispersal distance revisited. Biol Bull 216:373-385

* Sievers M, Dempster T, Fitridge I, Keough MJ (2014) Monitoring biofouling communities could reduce impacts to mussel aquaculture by allowing synchronisation of husbandry techniques with peaks in settlement. Biofouling 30:203-212

Sievers M, Dempster T, Keough MJ, Fitridge I (2019) Methods to prevent and treat biofouling in shellfish aquaculture. Aquaculture 505:263-270

Simkanin C, Davidson IC, Dower JF, Jamieson G, Therriault TW (2012) Anthropogenic structures and the infiltration of natural benthos by invasive ascidians. PSZNI: Mar Ecol 33:499-511

Soliman T, Inglis GJ (2018) Forecasting the economic impacts of two biofouling invaders on aquaculture production of green-lipped mussels Perna canaliculus in New Zealand. Aquacult Environ Interact 10:1-12

South PM, Floerl O, Forrest BM, Thomsen MS (2017) A review of three decades of research on the invasive kelp

Editorial responsibility: Brett Dumbauld, Newport, Oregon, USA
Undaria pinnatifida in Australasia: An assessment of its success, impacts and status as one of the world's worst invaders. Mar Environ Res 131:243-257

* South PM, Floerl O, Jeffs AG (2019) The role of biofouling development in the loss of seed mussels in aquaculture. Biofouling 35:259-272

Stenton-Dozey J, Broekhuizen N (2019) Provision of ecological and ecosystem services by mussel farming in the Marlborough Sounds. A literature review in context of the state of the environment pre and post-mussel farming. Prepared for Marine Farming Association, National Institute of Water \& Atmospheric Research, Christchurch

Strand $\varnothing$, Ferreira JG (2019) Introduction to regulating services. In: Smaal AC, Ferreira JG, Grant J, Petersen JK, Strand $\varnothing$ (eds) Goods and services of marine bivalves. Springer, Cham, p 115-117

* Toupoint N, Gilmore-Solomon L, Bourque F, Myrand B, Pernet F, Olivier F, Tremblay R (2012) Match/mismatch between the Mytilus edulis larval supply and seston quality: effect on recruitment. Ecology 93:1922-1934

*Vila M, Ibáñez I (2011) Plant invasions in the landscape. Landsc Ecol 26:461-472

W Watanabe S, Metaxas A, Scheibling RE (2009) Dispersal potential of the invasive green alga Codium fragile ssp. fragile. J Exp Mar Biol Ecol 381:114-125

*Waters CN, Zalasiewicz J, Summerhayes C, Barnosky AD and others (2016) The Anthropocene is functionally and stratigraphically distinct from the Holocene. Science 351: aad2622

Watts AM (2014) Biofouling patterns and local dispersal in an aquaculture system in the Marlborough Sounds, New Zealand. MSc thesis, University of Canterbury

WWatts A, Goldstien S, Hopkins G (2015) Characterising biofouling communities on mussel farms along an environmental gradient: a step towards improved risk management. Aquacult Environ Interact 8:15-30

Wong NA, McClary D, Sewell MA (2011) The reproductive ecology of the invasive ascidian, Styela clava, in Auckland Harbour, New Zealand. Mar Biol 158:2775-2785

*Woods CMC, Floerl O, Hayden BJ (2012) Biofouling on Greenshell ${ }^{\mathrm{TM}}$ mussel (Perna canaliculus) farms: a preliminary assessment and potential implications for sustainable aquaculture practices. Aquacult Int 20:537-557

* Ye N, Zhang X, Mao Y, Liang C and others (2011) 'Green tides' are overwhelming the coastline of our blue planet: taking the world's largest example. Ecol Res 26: 477-485

Zulkifly SB, Graham JM, Young EB, Mayer RJ, Piotrowski MJ, Smith I, Graham LE (2013) The Genus Cladophora Kützing (Ulvophyceae) as a globally distributed ecological engineer. J Phycol 49:1-17

Submitted: June 4, 2020; Accepted: September 14, 2020

Proofs received from author(s): November 10, 2020 